\title{
Surface Morphology in the Ablation Area of the Khumbu Glacier*,**
}

\author{
Shuji Iwata***, Okitsugu Watanabe****, and Hiroji Fushimi****
}

\begin{abstract}
The surface morphology of the ablation area of the Khumbu Glacier in east Nepal was surveyed and the details were mapped. The ablation area includes a bare ice area as well as a debris-covered area. Of the complex surface morphologies, large debris-covered cones, large hollows, and irregular uneven surfaces can be identified. The irregular uneven surfaces are subdivided into eleven morphological units according to the morphological elements such as relative relief, directional features of ridges, and distribution of ice cliffs, lakes, and streams. The surface morphology change both in transverse and in longitudinal direction of the glacier.
\end{abstract}

\section{Introdudction}

It is well known that the surface morphology of a stagnant debris-covered glacier is extreme complex (e.g. Price, 1973; Sugden and John, 1976), but there are few studies of the morphology itself. Sharp (1949) has described the small scale surfaceforms and Clayton (1964) and Healy (1975) have discussed the analogy between the morphology of the stagnant ice and the karst topography. For the mechanism of glacial deposition, the depositional landscape formed in the Ice Ages, and the complete system of morphological classification of glaciers, it is very important to understand the morphology of the debirs-covered area of the glacier and the facies of the supraglacial debris.

In Khumbu Himal there exist many debriscovered glaciers (e.g., Moribayashi and Higuchi, 1977), but the nature of the surface morphologies of them are hardly known. In this paper, the writers clarify the surface morphology in the ablation area of the Khumbu Glacier, east Nepal, based on an intensive topographical survey in the field during the summer season in 1978.

* Glaciological Expedition of Nepal, Contribution No. 63

** Project Report No. 2 on "Studies on Supraglacial Debris of the Khumbu Glacier"

*** Department of Geography, Tokyo Metropolitan University, Setagaya-ku, Tokyo 158

**** Water Research Institute, Nagoya University, Nagoya 464

\section{Survey}

Often described as irregular or chaotic, the character of the morphology of debris-covered glaciers have previously been undefined. Therefore, the first step is for the exact morphology to be represented by a suitable topographical survey. A simple terrestrial photogrammetry was carried out over the whole area of the Khumbu Glacier. At constant intervals along the top of the lateral moraine ridge of the Lobuche II stage (Iwata, 1976), about 400 stereopairs of photographs were taken by a $35 \mathrm{~mm}$ camera which was mounted on a plane table. Using these photographs, the positions of the key forms were fixed graphically. The details of the morphology were drawn from these ground photographs and the 50 oblique aerial photographs (including stereopairs and almost vertical photographs) taken in October and December, 1978 (Fushimi et al, 1980). The completed map, a scale of 1:5,000, represents large stones, debriscovered ridges, ice cliffs, lakes, streams, bare ice area, and ridges with ice pinnacles (Appendix, separate sheet 1 ).

In order to investigate forms on a small scale, large-scale maps were made in four detailed research area (Watanabe et al, 1980). In the first, second and third areas, contoured maps were made at 1:1,000 by framework surveying with a Wild $\mathrm{T} 2$ theodlite, and plane table surveying. The 4 th area was mapped on a 1:2,500 scale by tacheometry (the use of stadia readings). 


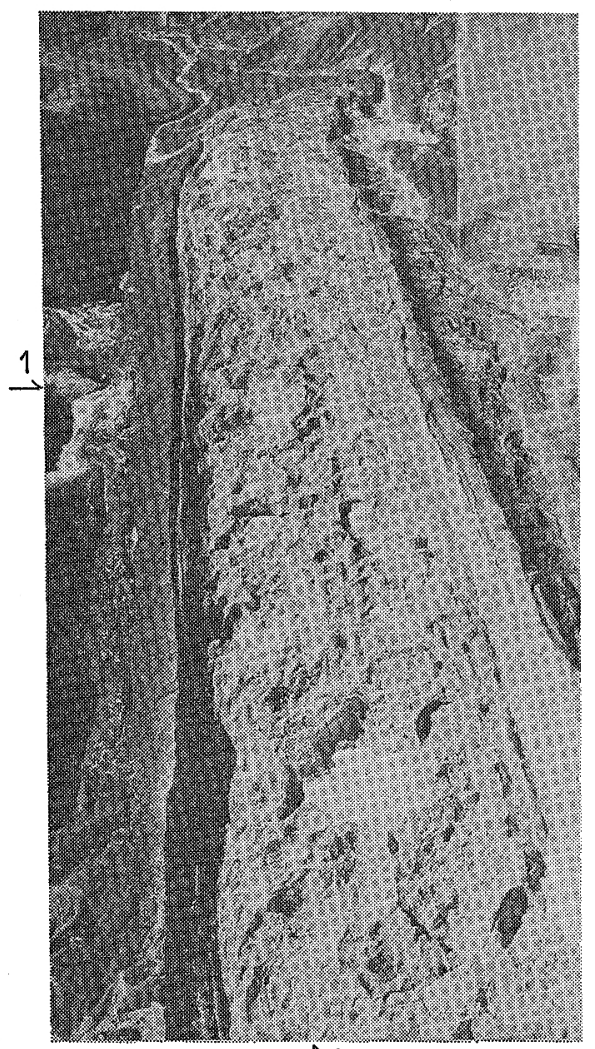

$r$

Fig. 1. The terminal $3 \mathrm{~km}$ of the Khumbu Glacier. 1: The clear boundary between unit 4 and unit 5 .

Sincees the series of surveys took place during the summer Monsoon period, they required many days due to the bad weather.

\section{Morphology}

\subsection{An outline}

The Khumbu Glacier is a compound glacier which the two main tributaries join the glacier from the West Cwm, as shown in Fig. 1 in Watanabe et al (1980). The ablation area of the Khumbu Glacier has a long and slender shape, with a length of 10 $\mathrm{km}$ and width of 0.5 to $1 \mathrm{~km}$, and is located at altitudes between 4,900 and $5,400 \mathrm{~m}$ (except for the ice fall which composes the uppermost part of the ablation area). Distinct lateral moraine ridges lie almost along the fringe of the ablation area.

The surface of the ablation area is divided into two: the bare ice area and the debris-covered area. The debris-covered area has very complicated surface morphology especially in the down-stream part (Fig. 1). The tangled distribution of melt hollows, ice

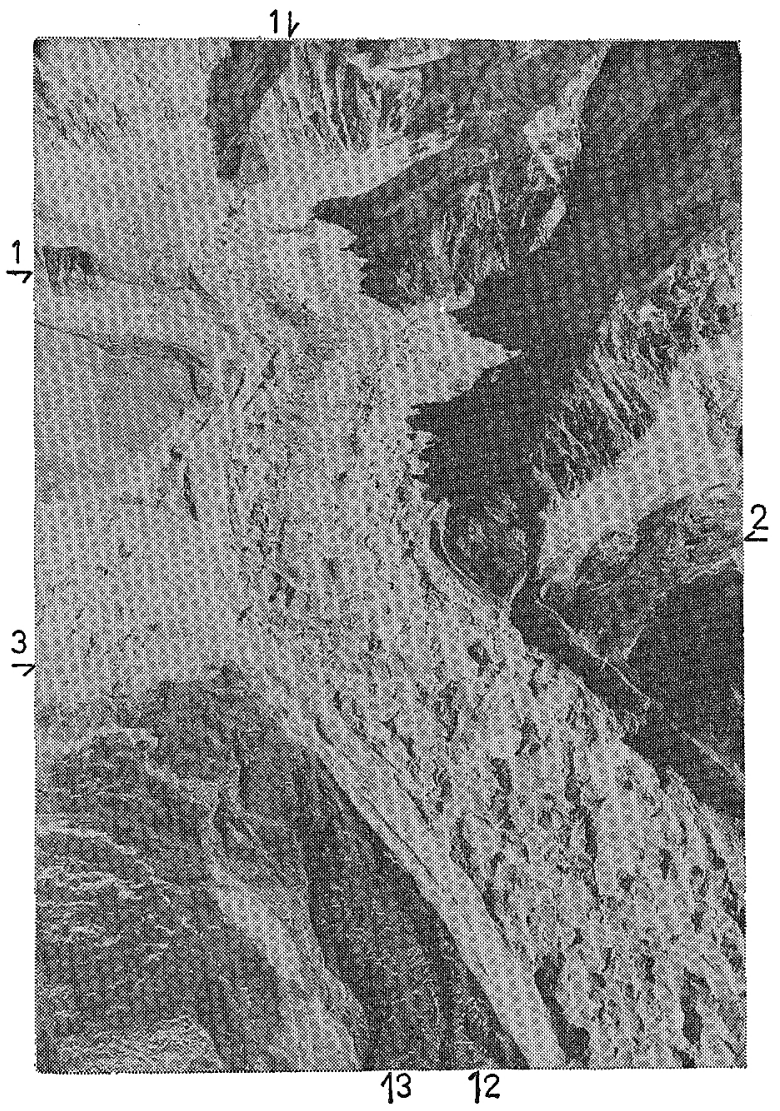

Fig. 2. The upper half (above $3.5 \mathrm{~km}$ upglacier from the terminus) of the ablation area of the Khumbu Glacier. The 2nd detailed research area is to the right in the foreground.

1: Stretch of bare ice area. 2: Landslide. 3: The clear boundary between unit 4 and units 6,7 .

slopes, ice pinnacles, lakes, and streams is shown on the glaciological map on about a 1:50,000 scale (Müller, 1959). The surface features become gentle and moderate in the section the $7.5 \mathrm{~km}$ upglacier from the terminus, and the bare ice area stretches along the center above there (Fig. 2).

\subsection{Lateral and terminal moraines}

The surface level of the Khumbu Glacier is lower than the lateral morain ridges almost in the ablation area (Fig. 1 and 2). While the lateral moraine of the right bank has a less steep inner-slope and a wider top-ridge, that of the left bank has a steeper inner-slope and a sharp top-ridge. In the $3 \mathrm{rd}$ detailed research area the height of the left bank moraine is lower than the opposite side. The reason is thought to be that the moraine was slump- 


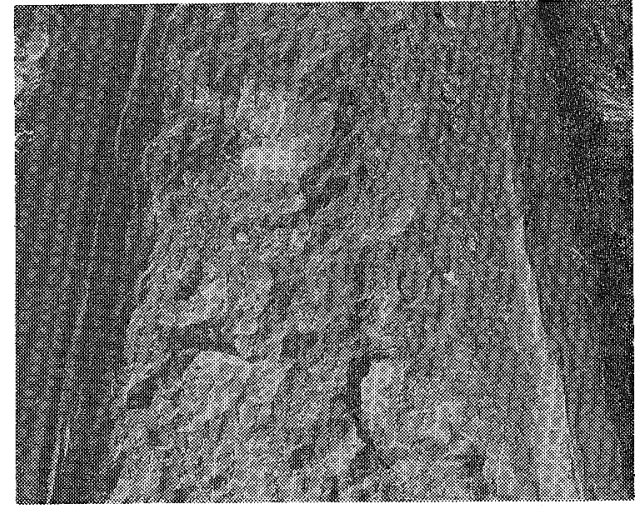

Fig. 3. The surface details in the area between $2 \mathrm{~km}$ and $2.5 \mathrm{~km}$ from the terminus. Note the funnel-shaped hollow (above left) and the hollows with ice cliffs and lakes. Parallel ridges are to the right. The up side is downglacier.

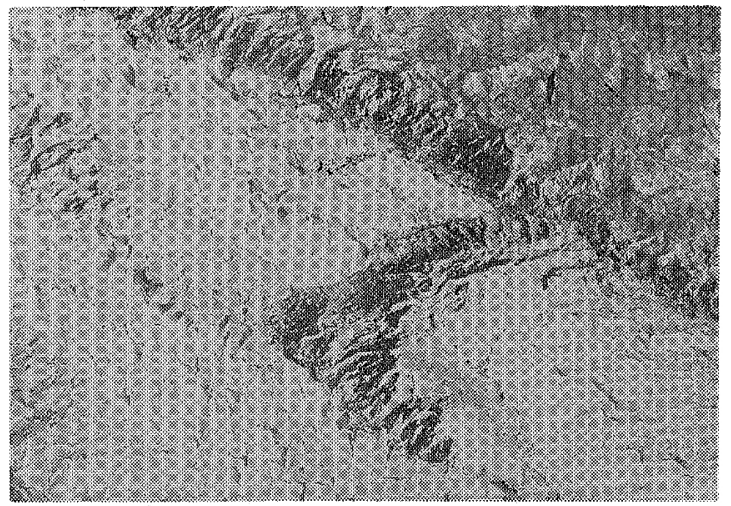

Fig. 4. The surface features of the 4th detailed research area. Above left is downglacier. The bare ice area with ice ridges and ogives stretches from above left to the below right. To the above right is the debris-covered part of the ice mass from Lingtren. Long and slender debris-covered area between the bare ice area stretches from above left to the center.

ed by a landslide which occurred behind it (Fig. 2). The surface level of the glacier rises higher than the lateral moraine ridges in the lowest part, and the terminus covers the former terminal moraine of the Lobuche II stage. The morphological features of the terminus of the Khumbu Glacier is very similar to an active rock glacier; the fresh frontal slope is divided with a sharp edge from the upper surface.

\subsection{Surface features of debris-covered area}

The distribution of the debris-covered ridges, ice cliffs, lakes, and streams per $125 \mathrm{~m}$ grid square were measured on the 1:5,000 map (Fig. 5). This figure shows the disproportionate distribution of these forms.

a) Debris-covered ridges and cones.

Despite the unevenness in the debris-covered area, some forms can be distinguished according to the surface features. In higher part, a debris-covered ridge, which is a chain of ridges or hills, and a debris-covered cone, which is a conical hill (Sharp, 1949), are recognized. Most ridges run in irregular directions, but in the lowest part and on the right bank side in the terminal $2 \mathrm{~km}$, the gentle debris-covered ridges lie parallel to each other (Fig. 3). A large debris-covered cone rises in the center of the 2 nd area and the 3rd area (Fig. 6). A series of large debris-covered cones lie along the contact line of the two ice masses from the West Cwm and Nuptse. In spite of the irregular unevenness of the debris-covered part, the long and slender debriscovered part between the stretches of bare ice, 7.5 $\mathrm{km}$ upglacier from the terminus, is linked series of smooth gentle knolls and ridges (Fig. 4).

b) Depressions, hollows, and lakes.

The lower part of the landforms are divided into a depression (shallow) and a hollow (deep) (Fig. 3). Some of them are occupied by lake water (Fig. 1, 2, 3 , and 7). There is a nearly round lake with a diameter of $200 \mathrm{~m}$ at about $3 \mathrm{~km}$ upglacier from the terminus (Fig. 1). A funnel-shaped hollow with lake such as shown in Fig. 3 is thought to be the most striking feature of the glacier karst (e.g. Clayton, 1964).

\section{c) Ice cliffs}

Ice cliffs are formed on flanks of debris-covered ridges and an banks of lakes (Fig. 1, 2, 3, and 7). Up to $2 \mathrm{~km}$ from the terminus, only few ice cliffs are scattered, but there are many high ice cliffs and bare ice slopes with steep angles in the 2nd area (Appendix, separate sheet 3). The debris on the glacier surface above the ice cliffs frequently falls with the rapid retreat of the cliffs and subsequently form the talus-like forms (Fig. 8).

\section{d) Streams}

The distribution of streams shows the disproportionate distribution. In particular, it hardly overlaps the distribution of lakes (Fig. 5-C, D). The streams, running down continuously from the 4th area, carves a deep gorge of which the wall on the left bank is a series of ice cliffs with height from 30 to $40 \mathrm{~m}$. The stream erodes the feet of the ice cliffs laterally, and then begin to disappear, entering into the sink hole just downglacier from the 


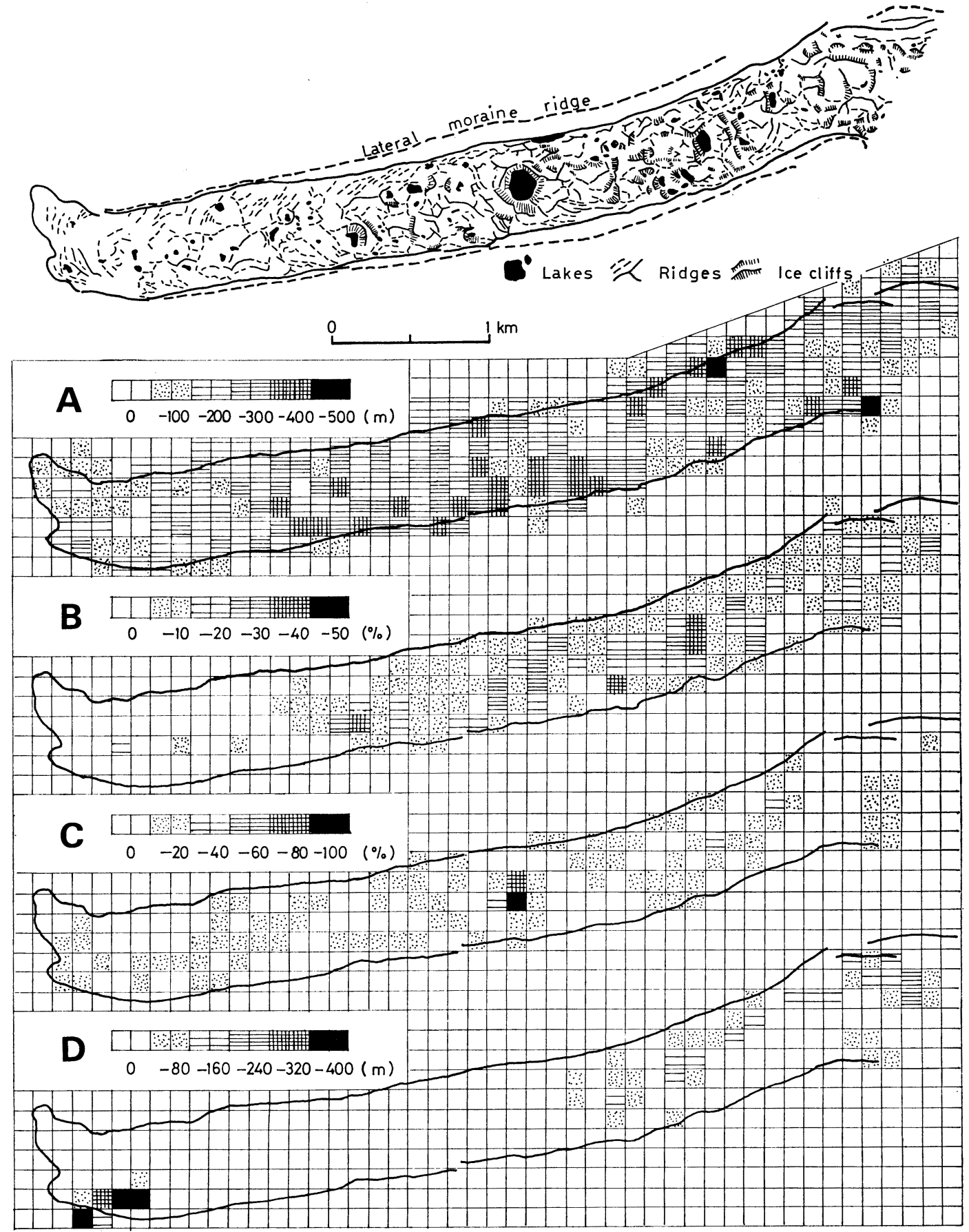

Fiig. 5. The surface forms and the distribution of the debirs-covered ridges (A), ice cliffs (B), lakes (C), and streams (D) per $125 \mathrm{~m}$ grid square in the ablation area up to $5.5 \mathrm{~km}$ from the terminus. 
$3 \mathrm{rd}$ area. There is no streams $0.5 \mathrm{~km}$ downglacier from the 2nd area at present, but the evidences of the past fluvial action are founded in several places.

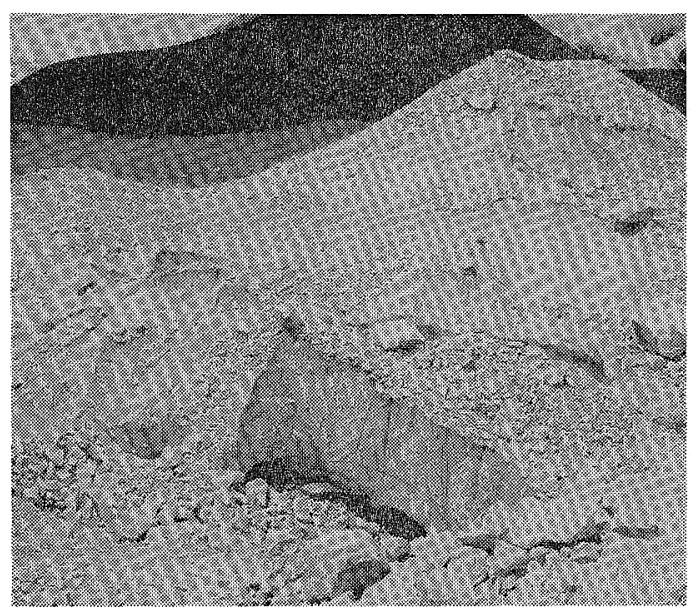

Fig. 6. A large debris-mantled cone and ice cliffs in the 3 rd detailed research area.

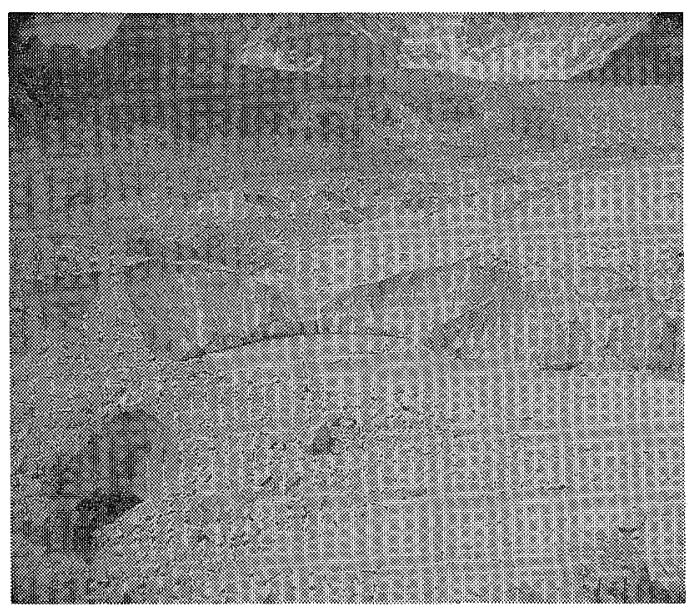

Fig. 7. Ice cliffs, lakes, and a sink-hole in the 2nd detailed research area.

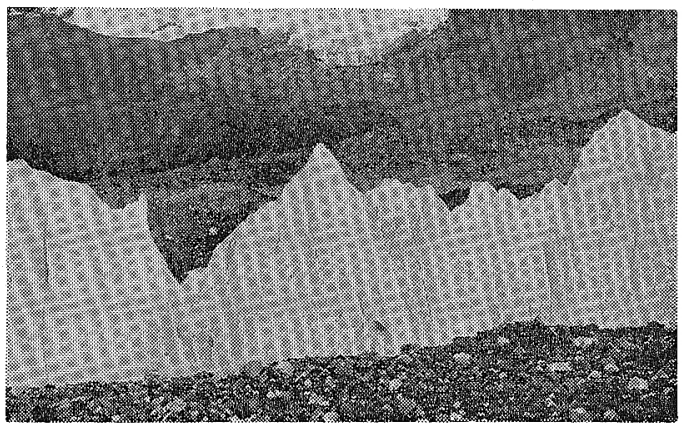

Fig. 8. Ice pinnacles in the 4th detailed research area.
These places are covered with sand and gravel worn by fluvial processes, and is sharply contrasted with the left bank side covered with large angular blocks.

There is a spectacular spout on the left bank side of the terminus and a large quantity of water under pressure is drained. In the 1950's, melt water issued from the other spout on the right bank (Müller, 1959).

\subsection{Surface features of bare ice area}

In the bare ice area, $7.5 \mathrm{~km}$ upglacier from the terminus, the relief mainly consists of ice ridges (Fig. 4). Ogives are formed below the icefall on the ice mass from the West Cwm, and display a striking directionality. They change to irregularly oriented ice ridges with many pinnacles (Fig. 8) as they move downglacier. On the bare ice surface, lakes hardly existed but small streams flow continuously down from the upper part in the summer season of 1978 .

\subsection{Relative relief}

Relative relief (relief energy) is the actual amount of relief within an area (Thornbury, 1954, p. 532). The values of the relative relief in the $1 \mathrm{st}, 2 \mathrm{nd}$, and 3rd areas are shown in Fig. 9. The relative relief is large in the 2nd area, where many high ice cliffs exist. Despite the importance of the distribution

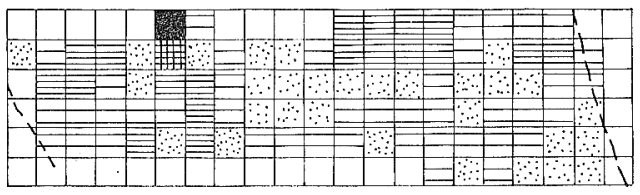

$3 r d$ area

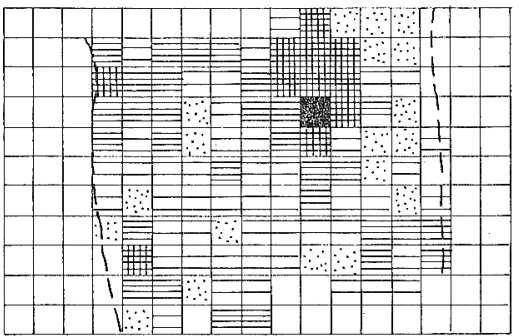
2nd area

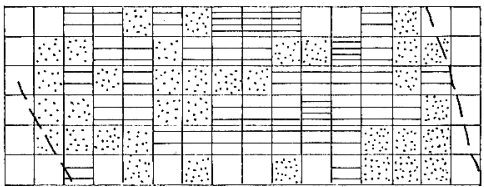

1st area

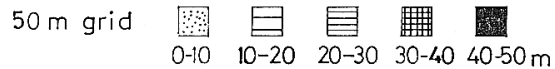

Fig. 9. The relative relief in the detailed research areas (per $50 \mathrm{~m}$ grid square). 


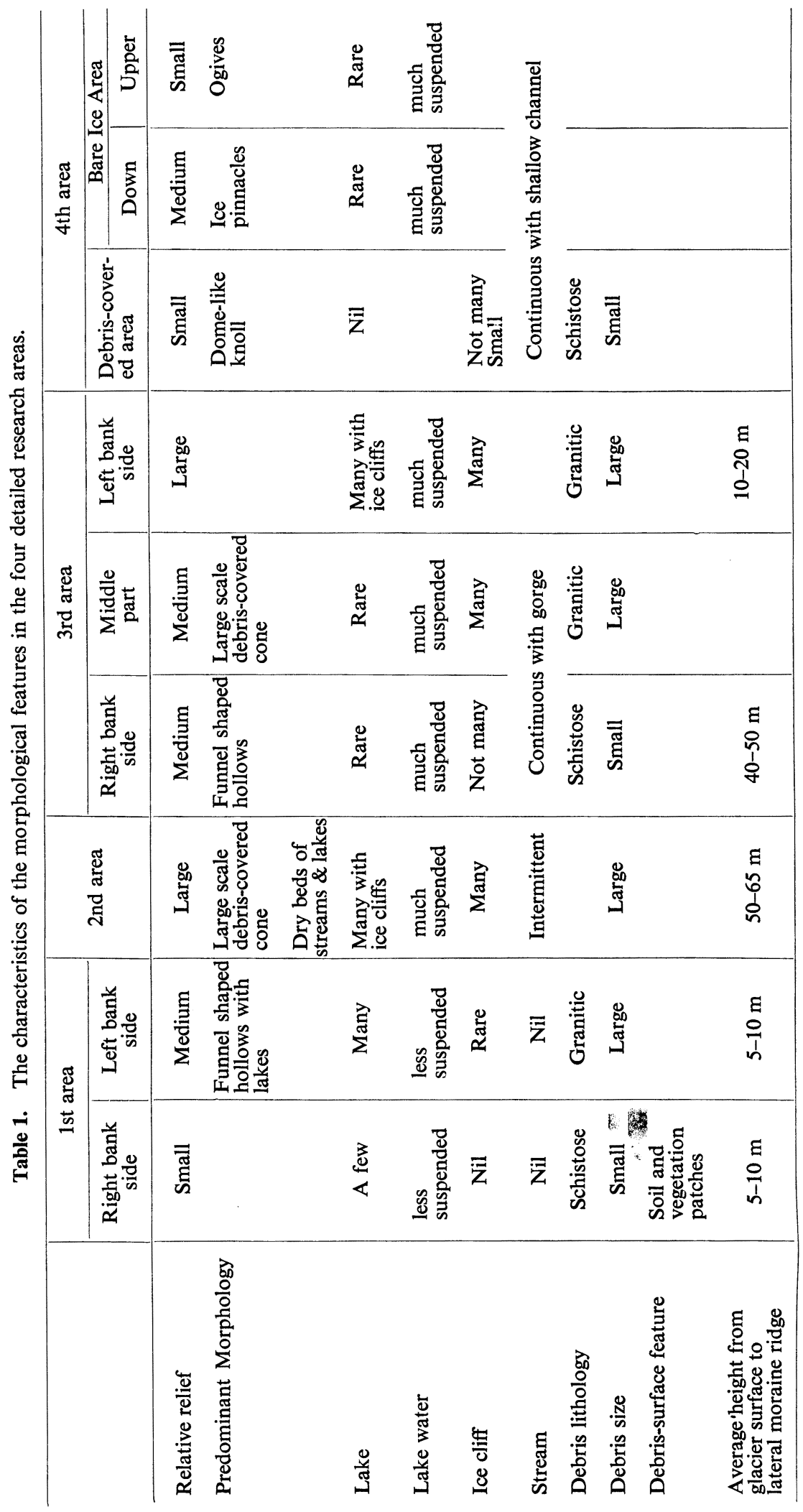




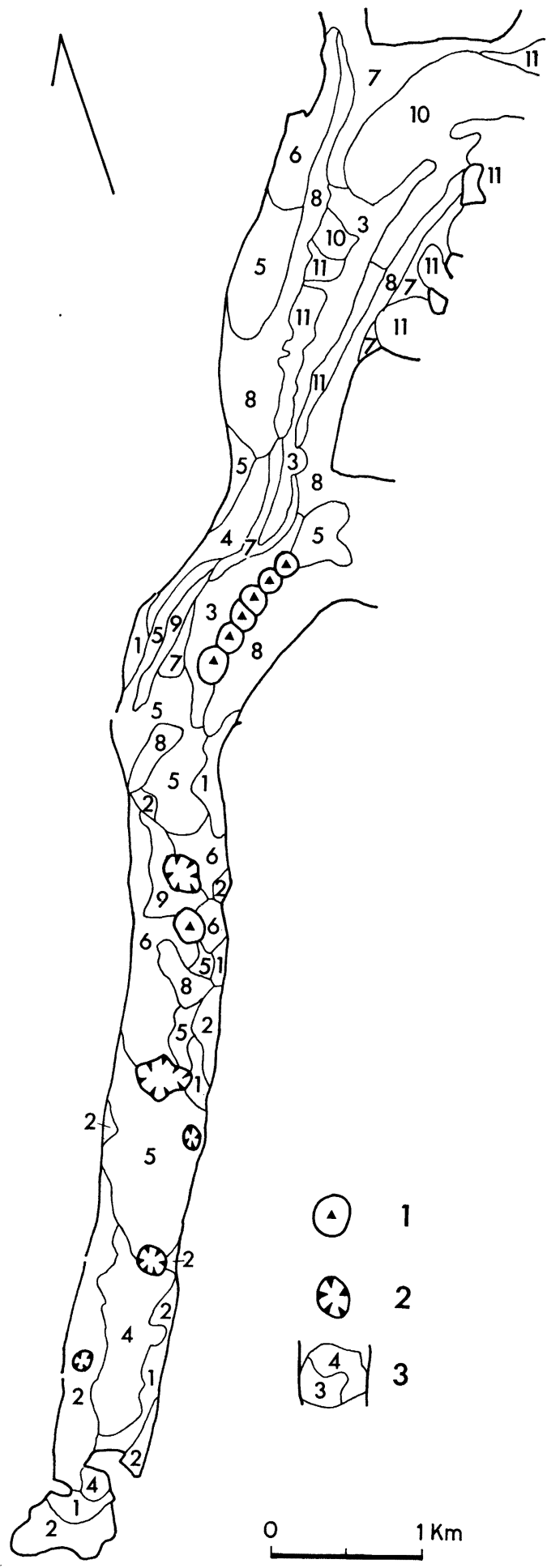

Fig. 10. of the surface relative relief, the quantitative value outside of these areas can not be shown because the 1:5,000 map (Appendix, separate sheet 1) not a contoured one. The length of the debris-covered ridges per an unit area (Fig. 4-A), however, is thought to indicate the nearly the same quantity as the relative relief. Accordingly, up to $2.5 \mathrm{~km}$ from the terminus, the relative relief is medium $(10-30 \mathrm{~m})$ and the largest values $(20-40 \mathrm{~m})$ are in the area between 2.5 and $4.5 \mathrm{~km}$ from the terminus. The relative relief becomes small in the area between 4.5 to $10 \mathrm{~km}$ upglacier from the terminus.

\subsection{Morphology in the detailed research area}

The characteristics of the morphological features in the four detailed research areas are given in Table 1. In these areas, special interest is attracted not only by the morphological differences depending on the location of the area, but also the relationship between the forms and both the debris features and processes that operate to form morphology. But, details will appear elsewhere.

\section{Discussion: A morphological classification}

A classification of the surface morphology in the ablation area was attempted on the 1:5,000 map (Fig. 10). The classified morphological units fall on the scale between $10^{3}$ to $10^{2} \mathrm{~m}$ in length (Fig. 10). The large debris-covered cone and the large hollow were separated, and the remainder, the irregularly uneven surface, was divided into the eleven morphological units given in Table 2. The eleven morphological units were obtained by combining the distribution of those surface features, such as the directional feature of ridges, exposure of glacier ice including the ice cliffs, lakes, streams, and relative relief. Those features are termed morphological elements.

This classification was easily made because it became obvious from the interpretation of aerial photographs and the observations in the field that the surface features change abruptly in many places. Such examples as the boundary between units 4 and 5 , located $2 \mathrm{~km}$ upglacier from the terminus (Fig. 1) and that between units of 6 and 7 and unit 5, $4.5 \mathrm{~km}$ from the terminus (Fig. 2), are pointed

Fig. 10. The classification of the surface according to a combination of the morphological elements.

1: Large debris-covered cone.

2: Large hollow.

3: Irregularly uneven surface. The numbers correspond to those in Table 2 . 
Table 2. Classification of the irregular-uneven surfaces.

\begin{tabular}{c|lc|l|l|l|l}
\hline $\begin{array}{c}\text { Number } \\
\text { of } \\
\text { Unit }\end{array}$ & \multicolumn{2}{|c|}{ Relative relief } & $\begin{array}{l}\text { Directional } \\
\text { feature of } \\
\text { ridges }\end{array}$ & Exposure of glacier ice & Lake & Stream \\
\hline 1 & Sma!l & $0-15 \mathrm{~m}$ & Nil & Nil & Rare & Nil \\
2 & Small & $0-10$ & Exist & Nil & Rare & Nil \\
3 & Small & $0-10$ & Nil & Small part & Nil & Nil \\
4 & Medium & $10-30$ & Nil & Very small part & A new & Nil \\
5 & Medium & $10-30$ & Nil & Large part & Many & Nil \\
6 & Large & $20-40$ & Nil & Large part & Many & Nil \\
7 & Small & $0-10$ & Nil & Large part & A few & Many \\
8 & Medium & $10-30$ & Nil & Large part & A few & Many \\
9 & Large & $20-40$ & Nil & Large part & A few & Many \\
10 & Small & $0-15$ & Exist & Whole & Rare & Rare \\
11 & Medium & $10-30$ & Nil & Whole & Rare & Rare \\
\hline
\end{tabular}

out. This indicates that morpho-genetic processes soil. The units 1,2 occupy in several places on the may change abruptly depending on the critical foot of the inner slope of the lateral moraine of the values of the certain parameters. Otherwise, it left bank. The upper most one $(5 \mathrm{~km}$ from the may be that the Khumbu Glacier is composed of terminus, the bank opposite Gorak Shep) is redifferent ice masses; these would be the lower, garded as a landslide deposit from the spur of middle, and upper ice masses in a longitudinal Nuptse located just upglacier (Fig. 2).

direction (Fushimi, 1977), and ice masses from the different tributury basins.

The difference of the surface morphology in the longitudinal direction on the glacier are shown in the distribution of the classified units. The distribution of the types of the units along the center line of the ablation area is the following order from upglacier:

Units 10, 11-Units 3, 7-Unit 5-Units 6, 8, 9-Unit 5-Unit 4-Units 2, 1

The difference of the surface morphology in the transverse direction on the glacier is clear in the area above $6 \mathrm{~km}$ from the terminus. The ice mass from the West Cwm represents gentle morphology with a bare ice surface, but both the marginal ice masses from tributary basins represent irregular debris-covered features, the same as in the downglacier area.

The thickness of debris cover is important as factors which govern the ablation. Correspondence between the morphological units and the debris thickness are exist. The units 3, 7 in the upper area have thin debris-covers, less than $5 \mathrm{~cm}$. On the contrary, the units 1,2 may be covered with thick debris. The units 1,2 are located at the terminal area, but some of them are in the upper area. The right-bank margin in the $3 \mathrm{rd}$ area, which is thought to be the terminal part of the ice mass from Lingtren, is an example with immature

The rate of the morphological change and the types of processes now operating must be investigated in every classified morphological unit. However, these details, based on measurements, will appear elsewhere: in this paper, only the close relation between the surface morphology and the existence of lakes, streams, and ice cliffs as well as thickness of debris cover is pointed out.

\section{Summery}

The distribution of 5 morphological elements, relative relief, directional feature of ridges, exposure of glacier ice including ice cliffs, lakes, and streams are shown. According to combine these morphological elements, a morphological classification is obtained. The large debris-covered cones, large hollows, and irregular uneven surface can be classified. The surface morphology change both in the transverse and longitudinal direction on the glacier. The summery of the longitudinal change of the morphology and the units is;

(i) The wide bare ice area in the upper section of the ablation area between $7 \mathrm{~km}$ and $10 \mathrm{~km}$ from the terminus is a row-relief gentle morphology with the micro unevenness such as ice pinnacles (Units $10,11,3,7)$.

(ii) In the section between $7 \mathrm{~km}$ and $4.5 \mathrm{~km}$ from the terminus, the relative relief increases and streams with high ice cliffs are found (Units 3, 7, 5). 
(iii) In the section $4.5 \mathrm{~km}$ to $2 \mathrm{~km}$ upglacier from the terminus which includes the 2 nd area, the relief attains the maximum and the morphology becomes very complicated. Many ice cliffs, lakes, and streams are located (Units 6, 8, 9).

(iv) The terminal $2 \mathrm{~km}$ shows the relatively moderate relief with thick debris-mantle (Units 5 , $4,2,1)$.

\section{Acknowledgements}

We thank Messrs J. Inoue, K. Ikegami, Y. Tanaka, M. Yoshida, Pasang Dawa Sherpa, and Tawa Lhakpa Sherpa, who assisted in the field.

\section{References}

Clayton, L. (1964): Karst topography on stagnant glaciers. Journal of Glaciology, Vol. 5, 107-112.

Fushimi, H. (1977): Structural studies of glaciers in the Khumbu region. Seppyo, Vol. 39, Special Issue, 30-39. .

Fushimi, H., Yasunari, T., Higuchi, H., Nagoshi, A., Watanabe, O., Ikegami, K., Higuchi, K., Ageta, Y., Ohata, T., and Nakajima, C. (1980): Preliminary report on flight observations of 1976 and 1978 in the Nepal Himalayas. in this issue.
Healy, T.R. (1975): Thermokarst-a mechanism of deicing ice-cored moraines. Boreas, Vol. 4, 19-23.

Iwata, S. (1976): Late Pleistocene and Holocene moraines in the Sagarmatha (Everest) region, Khumbu Himal. Seppyo, Vol. 38, Special Issue, 109114.

Moribayashi, S. and Higuchi, K. (1977): Characteristics of glaciers in the Khumbu region and their recent variations. Seppyo, Vol. 39, Special Issue, 3-6.

Muller, F. (1959): Eight months of glacier and soil research in the Everest region. In the Mountain World, 1958-59, Zurich, 191-208.

Price, R.J.(1973): Glacial and Fluvioglacial Landforms. Oliver and Boyd, Edinburgh, $242 \mathrm{pp}$.

Sharp, R.P. (1949): Studies of superglacial debris in valley glaciers. American Journal of Science, Vol. 247, 289-315.

Sugden, D. and John, B.S. (1976): Glaciers and Landscape. Edward Arnold, London, 376 pp.

Tohrnbury, W.D. (1954): Principles of Geomorphology. Wiley, New York, $618 \mathrm{pp}$.

Watanabe, O., Fushimi, H., Inoue, J., Iwata S., Ikegami, K., Tanaka, Y., Yoshida, M., and Upadhyaya, B. (1980): Outline of debris cover project in Khumbu Glacier. in this issue. 